\title{
Are patients comfortable with medical students examining them?
}

\author{
SHRUTHI RAVISHANKAR
}

\begin{abstract}
A key feature of medical curricula across the world is the interaction of medical students with patients at teaching hospitals. However, patients may not be comfortable engaging with medical students in certain situations, and there are a number of possible reasons for this. Teaching hospitals often overlook the need to take consent for such interactions. Certain measures can be taken to increase the confidence of patients in the medical students treating them. Studies on the subject make it clear that this ethical question is common throughout the world.
\end{abstract}

Keywords: Medical students, patient interaction, informed consent

\section{Introduction}

All over the world, medical students are introduced to the art of clinical examinations and history taking through supervised interaction with patients at teaching hospitals. They are called at once if there is a unique case, or one with the classic presentation of a disease on which they may be tested in examinations. As the patient lies down, $s /$ he is surrounded by a number of young medical stu-dents with limited skills, and is examined by each of them in turn.

Obviously, to become the doctors of the future, these students must get a certain amount of exposure to clinical methods and real patients before they graduate. The question is: Are the patients receptive to this idea? Would a woman in labour give her consent freely to a couple of inexperienced medical students staring at her when she is in pain? This article looks at what patients might feel about medical students interacting with them and examining them.

Author: Shruthi Ravishankar (shruthi.sunshankar@gmail.com), Second Year MBBS Student, Madras Medical College, Chennai, Tamil Nadu 600003 INDIA.

To cite: Ravishankar S. Are patients comfortable with medical students examining them?. Published online first on May 15, 2021. DOI: 10.20529/ IJME.2021.038.

Manuscript Editor:Vijayaprasad Gopichandran

(c) Indian Journal of Medical Ethics 2021
It also looks at how teaching hospitals communicate with patients to take consent to being examined by medical students.

\section{The several layers of being comfortable}

Medical students' interactions with their patients are of many types. This leads to vast differences in how patients perceive these interactions. One common issue is the gender of the patient and that of the doctor. In a study conducted at a British breast clinic, only $30 \%$ of patients were comfortable with a male medical student taking their history compared to $48 \%$ with a female medical student. Only $23 \%$ of patients were comfortable with a male medical student examining them compared to $45 \%$ with a female medical student (1). The fact that female patients were less comfortable with being examined by male medical students has also been noted in several other studies $(2,3)$.

Another issue is the blind, open-ended consent taken in several teaching hospitals. These hospitals assume that if patients are comfortable with their history being taken by a medical student, they will be comfortable with having medical students conduct even an invasive examination on them. Patients, however, have different levels of comfort with different types of interaction. Those in outpatient clinics are generally more receptive to medical students being involved. This is because of the nature of interaction, which is generally observation, history taking and conducting a non- invasive examination. However, patients in inpatient wards may be uncomfortable or completely unwilling to allow medical students to examine them, or perform any procedure or invasive examinations on them. This could be because patients do not have complete confidence in the students' skills, or because of a general discomfort with medical students performing these procedures (3). A US study by Graber et al, found that the majority of patients in the emergency room would not let medical students perform any procedure, including venepuncture (4).

\section{When patients are not completely informed}

While involving medical students in direct patient interaction is an ethical conundrum in itself, the problem deepens when this is done without the patients' informed consent. In a 1987 study con-ducted by Cohen et al, only $37.5 \%$ of all responding teaching hospitals specifically informed pa-tients that students would be involved in their care (5). In another more 
recent study, only $48 \%$ of participants knew they could be the first patient on whom a medical student might perform a pro-cedure, though a total of $66 \%$ thought they should be told if a student was performing his or her first procedure on them (6). This is no longer just an ethical question then, but potentially a legal tangle. If something untoward happens, it is difficult to determine who was incorrect the mini-mally skilled medical student or the teacher who allowed the student to perform a procedure.

There is little or no information on whether consent is obtained in teaching hospitals in low- and middle-income countries. This presents a more worrying picture, and if the information is made available, it could potentially open a Pandora's box. The majority of teaching hospitals are run by the government and their patient population is predominantly from the lower socio-economic classes (7). It is unlikely that the doctors in these teaching hospitals inform their patients that medical students will be involved in their care. It is doubtful that patients are asked to give their consent to the same.

\section{What can be done?}

The first thing that must be done is to properly sensitise medical students to the challenges they will face, the caution they must use, and the care that they must provide to their patients. They must receive this sensitisation before they meet patients for the first time. Every medical student must be aware that the patient's consent is absolutely necessary to perform any examination, or even to take a history. They must be aware of the importance of explaining, clearly, who they are and what they intend to do. This instruction has been found to be lacking in several medical schools across the world. One study noted that only 51 percent of those responding medical schools which specifically gave their students instructions on initial patient interaction, insisted as a matter of policy that they introduce themselves as students and clarify their role in patient care (5). Students who do not receive formal training in ethics and in medical studentpatient relations are likely to have a low level of awareness of consent. This is certainly the case in several developing countries (8).

One way to take the patient into confidence is by improving and developing communication skills, especially clinical communication. While this is emphasised in Western medical schools, in devel-oping countries such as India, formal training in these skills has been fragmented and uneven in most medical curricula (9). Another way to make patients feel more comfortable is to reduce the student-patient ratio in an interaction, with just a few students interacting with a patient at a time, compared to several students in the same room with a patient.
Improving the skills of medical students before they directly interact with patients will make them more confident when they are actually part of these interactions. This training can be done using mannequins and models. Of course, modern technology has brought the gift of patient simulators using artificial intelligence and virtual reality (5).

\section{Conclusion}

Despite several such challenges, the attitude of patients towards student-doctors is positive. In a review of 16 studies by $\mathrm{Mol}$ et al, many patients felt altruistic and valued for contributing to the future of medicine by helping young doctors learn (10). It is imperative that successive generations of medical students benefit from such a perspective; teaching hospitals and medical students need to take a few steps to cement the student-patient relationship.

The student-patient interaction is of invaluable importance in shaping a medical student's approach to medical practice. However, the importance of consent must be emphasised to both teachers and students, and patients must be taken into complete confidence. This would make the whole experience educative and informative for medical students, and fulfilling for patients.

\section{Competing interests and funding: None declared.}

\section{References}

1. Carmichael AR, Nevill AM, Sami AS, Mayr G. The attitude of patients towards the presence of medical students in a breast clinic: A selfadministered questionnaire based audit. J Biosafety Health Educ. 2014;2:1. Doi: 10.4172/2332-0893.1000115.

2. Marwan Y, Al-Saddique M, Hassan A, Karim J, Al-Saleh M. Are medical students accepted by patients in teaching hospitals?. Med Educ Online. 2012;17(1):17172. Doi:10.3402/meo.v17i0.17172

3. Aljoudi SB, Alsolami SS, Farahat FM, Alsaywid B, Abuznadah W. Patients' attitudes towards the participation of medical students in clinical examination and care in Western Saudi Ara-bia. J Fam Community Med. 2016;23(3):172-178. Doi:10.4103/2230-8229.189133

4. Graber MA, Pierre J, Charlton M. Patient opinions and attitudes toward medical student proce-dures in the emergency department. Acad Emerg Med. 2003 Dec;10(12):1329-33. Doi:10.1111/j.15532712.2003.tb00006.x

5. Cohen DL, McCullough LB, Kessel RW, Apostolides AY, Alden ER, Heiderich KJ. Informed consent policies governing medical students' interactions with patients. J Med Educ. 1987 Oct;62(10):789-798. Doi: 10.1097/00001888-198710000-00001

6. Santen SA, Hemphill RR, Spanier CM, Fletcher ND. 'Sorry, it's my first time!' Will patients consent to medical students learning procedures?. Med Educ. 2005 Apr;39(4):365-9. Doi:10.1111/j.13652929.2005.02113.x

7. Rajpurohit S. 'Government Hospitals are for the poor.' Hindu Business Line. 2012 Dec19.

8. Rameshkumar K. Ethics in medical curriculum; Ethics by the teachers for students and socie-ty. Indian J Urol. 2009;25(3):337-9. Doi: 10.4103/0970-1591.56192

9. Modi JN, Anshu, Chhatwal J, Gupta P, Singh T. Teaching and Assessing Communication Skills in Medical Undergraduate Training. Indian Pediatr. 2016;53(6):497-504. Doi:10.1007/s13312-016-0879-z

10. Mol SS, Peelen JH, Kuyvenhoven MM. Patients' views on student participation in general prac-tice consultations: a comprehensive review. Med Teach. 2011;33(7):e397-e400. Doi:10.3109/0142159X. 2011.581712. 